
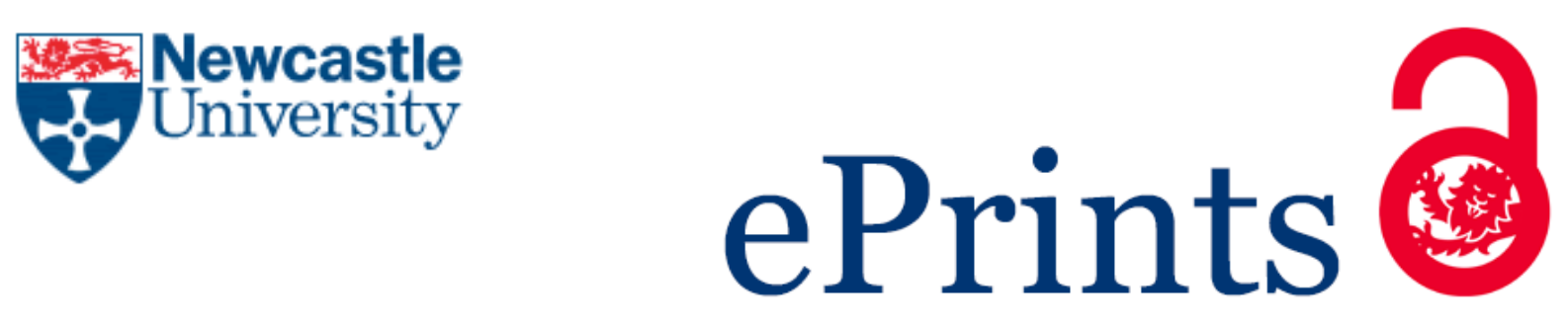

Listl S, Broadbent J, Thomson MT, Stock C, Shen J, Steele J, Wildman J,

Heilmann A, Watt RG, Tsakos G, Peres MA, van der Heijden G, Jurges H. Childhood socioeconomic conditions and teeth in older adulthood: evidence from SHARE wave 5.

Community Dentistry and Oral Epidemiology (2017)

DOI: https://doi.org/10.1111/cdoe.12332

\title{
Copyright:
}

This is the peer reviewed version of the following article, which has been published in final form at https://doi.org/10.1111/cdoe.12332. This article may be used for non-commercial purposes in accordance with Wiley Terms and Conditions for Self-Archiving.

Date deposited:

01/09/2017

Embargo release date:

19 September 2018 


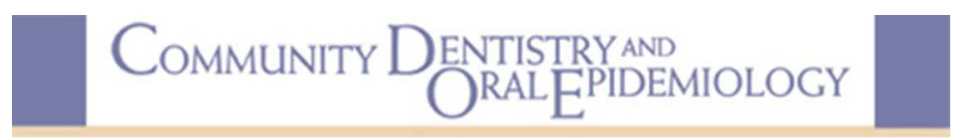

\section{Childhood socioeconomic conditions and teeth in older adulthood: evidence from SHARE wave 5}

\begin{tabular}{|c|c|}
\hline Journal: & Community Dentistry and Oral Epidemiology \\
\hline Manuscript ID & CDOE-16-477.R3 \\
\hline Manuscript Type: & Original Manuscript \\
\hline Date Submitted by the Author: & $n / a$ \\
\hline Complete List of Authors: & $\begin{array}{l}\text { Listl, Stefan; Radboudumc, Quality and Safety of Oral Health Care; } \\
\text { University of Heidelberg, Department of Conservative Dentistry } \\
\text { Broadbent, Jonathan; Faculty of Dentistry, University of Otago, Oral } \\
\text { Rehabilitation } \\
\text { Thomson, W Murray; School of Dentistry, Dunedin, New Zealand, Oral } \\
\text { Sciences, Sir John walsh research Institute } \\
\text { Stock, Christian; University of Heidelberg, Institute of Medical Biometry } \\
\text { and Informatics } \\
\text { Shen, Jing } \\
\text { Steele, Jimmy; Newcastle University, School of Dental Sciences; } \\
\text { Wildman, John; Newcastle University } \\
\text { Heilmann, Anja; UCL, Epidemiology \& Public Health } \\
\text { Watt, Richard; University College London, Epidemiology and Public Health } \\
\text { Tsakos, Georgios; University College London, Department of Epidemiology } \\
\text { and Public Health } \\
\text { Peres, Marco; The University of Adelaide, School of Dentistry, Australian } \\
\text { Research Centre for Population Oral Health } \\
\text { van der Heijden, Geert; ACTA, Social Dentistry } \\
\text { Jürges, Hendrik; University of Wuppertal, Schumpeter School of Business } \\
\text { and Economics }\end{array}$ \\
\hline Keywords: & dentition, child, Tooth loss, Adults, Social inequality \\
\hline Abstract: & $\begin{array}{l}\text { Objectives: Dental diseases are the most common chronic diseases } \\
\text { worldwide. Healthy teeth are vital for quality of life, particularly diet and } \\
\text { nutrition. However, little information exists to inform health policy makers } \\
\text { about potentially long-lasting influences of early life conditions. The } \\
\text { purpose of this study was to investigate the relation between early life } \\
\text { socioeconomic conditions and number of natural teeth at age } 50 \text { and } \\
\text { above. Methods: Analyses were conducted on cross-sectional data from the } \\
\text { Survey of Health, Ageing, and Retirement in Europe (SHARE wave 5), } \\
\text { which includes information on } 60,674 \text { respondents aged } 50 \text { years or older } \\
\text { from } 14 \text { European countries and Israel. Using SHARE life history } \\
\text { information, a series of regression models (OLS, Tobit) were estimated to } \\
\text { analyse the relationship between socioeconomic conditions in earlier life } \\
\text { and the number of teeth at age } 50+\text {. Results: Childhood socioeconomic } \\
\text { background was associated with the number of natural teeth at age } 50 \text { and } \\
\text { above, even after controlling for current determinants of oral health. } \\
\text { Respondents who had had more than } 25 \text { books in their childhood }\end{array}$ \\
\hline
\end{tabular}


household had a mean 1.4 (95\% CI: $1.2-1.5)$ more teeth than respondents with fewer books. Respondents who reported poor financial conditions during childhood had a mean 0.6 (95\% CI: 0.3-0.9) fewer teeth than respondents who reported better financial conditions in childhood. Conclusion: These findings substantiate the association between socioeconomic conditions in the early years of life and tooth retention to older adulthood and highlight the long-lasting relation between childhood living conditions and oral health through the lifecourse.

SCHOLARONE ${ }^{\text {m }}$

Manuscripts 
Title: Childhood socioeconomic conditions and teeth in older adulthood: evidence from SHARE wave 5

Name of Authors: Stefan Listt ${ }^{1,2}$, Jonathan M Broadbent ${ }^{3}$, W. Murray Thomson ${ }^{3}$, Christian Stock ${ }^{4}$, Jing Shen $^{5}$, Jimmy Steele ${ }^{5}$, John Wildman ${ }^{5}$, Anja Heilmann ${ }^{6}$, Richard G Watt ${ }^{6}$, Georgios Tsakos ${ }^{6}$, Marco A Peres $^{7}$, Geert van der Heijden ${ }^{8}$, Hendrik Jürges ${ }^{9}$

Institutional affiliations:

${ }^{1}$ Department of Quality and Safety of Oral Health Care, Radboud University Nijmegen, Nijmegen, The Netherlands

2 Translational Health Economics Group (THE Group), Heidelberg University, Department of Conservative Dentistry, Heidelberg, Germany

${ }^{3}$ Sir John Walsh Research Institute, Faculty of Dentistry, University of Otago, Dunedin, New Zealand

${ }^{4}$ Institute of Medical Biometry and Informatics, Heidelberg University, Heidelberg, Germany

${ }^{5}$ Newcastle University, Newcastle upon Tyne, United Kingdom

${ }^{6}$ University College London, Department of Epidemiology and Public Health, London, United Kingdom

${ }^{7}$ University of Adelaide, Australian Research Centre for Population Oral Health (ARCPOH), Australia

${ }^{8}$ Department of Social Dentistry, Academic Centre for Dentistry Amsterdam (ACTA), University of Amsterdam and VU University Amsterdam, Amsterdam, Netherlands

${ }^{9}$ Schumpeter School of Business and Economics, University of Wuppertal, Wuppertal, Germany

Corresponding author: Stefan Listl, Heidelberg University, Translational Health Economics Group, Im Neuenheimer Feld 400, 69120 Heidelberg, Germany; stefan.listl@med.uni-heidelberg.de

Word count (text): 3845 
Childhood socioeconomic conditions and teeth in older adulthood: evidence from SHARE wave 5

\begin{abstract}
Objectives: Dental diseases are the most common chronic diseases worldwide. Healthy teeth are vital for quality of life, particularly diet and nutrition. However, little information exists to inform health policy makers about potentially long-lasting influences of early life conditions. The purpose of this study was to investigate the relation between early life socioeconomic conditions and number of natural teeth at age 50 and above. Methods: Analyses were conducted on cross-sectional data from the Survey of Health, Ageing, and Retirement in Europe (SHARE wave 5), which includes information on 60,674 respondents aged 50 years or older from 14 European countries and Israel. Using SHARE life history information, a series of regression models (OLS, Tobit) were estimated to analyse the relationship between socioeconomic conditions in earlier life and the number of teeth at age 50+. Results: Childhood socioeconomic background was associated with the number of natural teeth at age 50 and above, even after controlling for current determinants of oral health. Respondents who had had more than 25 books in their childhood household had a mean 1.4 (95\% CI: 1.2-1.5) more teeth than respondents with fewer books. Respondents who reported poor financial conditions during childhood had a mean 0.6 (95\% CI: 0.3-0.9) fewer teeth than respondents who reported better financial conditions in childhood. Conclusion: These findings substantiate the association between socioeconomic conditions in the early years of life and tooth retention to older adulthood and highlight the long-lasting relation between childhood living conditions and oral health through the lifecourse.
\end{abstract}

Key words: dentition, child, adult, aged, socioeconomic status, dental care 


\section{INTRODUCTION}

Dental diseases are globally among the most frequent ${ }^{1}$ and most costly ${ }^{2}$ diseases to treat. Healthy teeth are important for (older) people's quality of life and wellbeing, not least due to their relevance for diet and nutrition. ${ }^{3,4}$ However, little information exists to inform health policy makers about potential longerterm benefits of promoting early life conditions in order to foster enduring tooth retention until old age.

Chronic diseases are increasingly being studied within a life-course framework. This particularly applies to the study of conditions such as coronary heart disease and diabetes. ${ }^{5-7}$ Several theoretical models have been established which describe pathways linking lifecourse exposures to later health and disease. ${ }^{8}$ These models postulate that exposures during a specific time window have an irreversible effect on later health (critical period model), or that exposures during developmental periods have a stronger effect than they would have at other times (sensitive period model), or that detrimental and beneficial exposures gradually accumulate throughout life (accumulation of risk model), or that one exposure leads to another exposure in a process that affects health in later life (chain of risk model).

To date, there are very few population-based birth cohort studies with clinical oral health data. Existing knowledge relies mainly on findings from the following three cohorts: the Newcastle (UK) Thousand Families birth cohort of 1947, the Dunedin (NZ) Multidisciplinary Health and Development Study birth cohort of 1972-73, and the Pelotas (Brazil) birth cohorts of 1982, 1993 and 2004. ${ }^{9-12}$ Findings from these studies highlight that socioeconomic background, early life health-related behaviours, and previous disease experience are important determinants of oral health in the first to fifth decades of life. ${ }^{12-15}$

However, the existing birth cohort studies are not yet able to follow up individuals' oral health into later adulthood (age 50 and above). ${ }^{16}$ Other studies based on cohort data that could have followed individuals into age 50+ have included relatively little detail about childhood conditions. ${ }^{17,18}$ The corresponding knowledge gap could be served by survey-based studies of older adults that contain information on current oral health status and, retrospectively, on circumstances in earlier life. A previous study based on 
multi-country data from the Survey of Health, Ageing and Retirement in Europe (SHARE) highlighted the important role of early life conditions, particularly childhood financial hardship; adverse life events affected chewing ability in middle and later adulthood. ${ }^{18}$ While chewing ability represents a relevant subjective measure of current oral health, the number of natural teeth (hereafter number of teeth) provides a more comprehensive oral health measure in older age because tooth loss indicates the accumulated impacts of adverse risks through the life course. ${ }^{19}$ In many high income countries, the number of missing teeth has been decreasing in adults in recent years, with more people maintaining a functional dentition (at least 20 remaining teeth), and the number of edentulous people showing a marked decline. ${ }^{20-23,49}$ Nevertheless, as considerable proportions of populations aged $50+$ are affected by tooth loss, and missing teeth have been shown to compromise quality of life, ${ }^{24}$ tooth loss still represents a public health problem and is a relevant marker of oral health. ${ }^{23}$

The aim of this study was to determine associations between childhood conditions - particularly aspects of socioeconomic status such as educational and financial circumstances of the family, and the number of teeth in populations aged 50+ from 14 European countries and Israel. We hypothesized that adverse childhood socioeconomic conditions are associated with retaining fewer natural teeth at age 50+.

\section{Methods}

This study utilizes data from the Survey of Health, Ageing, and Retirement in Europe (SHARE) and includes samples from Austria, Belgium, Czech Republic, Denmark, Estonia, France, Germany, Israel, Italy, Luxembourg, Netherlands, Slovenia, Spain, Sweden, and Switzerland. SHARE is a large panel database of microdata on health, socioeconomic status and social and family networks covering countries of the European Union and Israel. ${ }^{25}$ So far, SHARE has released data from 5 waves $(2004 / 05,2006 / 07$, $2008 / 09,2010 / 11,2013$ ) comprising more than 220,000 interviews of about 110,000 individuals aged 50 or over. SHARE samples were drawn to be representative of the older adult population (age 50+) in each country. Various types of survey sample design were used, such as simple random sampling in Sweden, and multistage sampling on basis of regional population registers in Italy. The initial wave of SHARE 
was conducted in 2004, followed by wave 2 which collected information on respondents' chewing ability in 2006-2007. Wave 3 (SHARELIFE) was conducted in 2008-2009 and collected retrospective information about elements of respondents' lives, ranging from relationships with partners, children, housing and work history to details on health and health care. SHARE wave 4 (2010-2011) did not include oral health outcome measures. SHARE wave 5 (release date: March $31^{\text {st }}$ 2015; collected in 2013) for the first time contained information on the respondents' numbers of teeth. ${ }^{25}$ Also, a novel "miniature version" of the SHARELIFE questionnaire focusing on childhood events was introduced in SHARE wave 5. Individual response rates in SHARE ranged from 55\% (Netherlands) to 85\% (Estonia) in longitudinal samples and from 25\% (Luxembourg) to 52\% (Czech Republic) in baseline/refreshment samples.

This study is based on SHARE wave 5 data and information on childhood events collated at that wave. Fieldwork for SHARE wave 5 started in February 2013 and was completed in November $2013 .^{26}$ The target population of wave 5 were individuals born in 1962 or earlier, and persons who are a spouse/partner of a person born in 1962 or earlier, who spoke (one of) the official language(s) of the country (regardless of nationality and citizenship) and who did not live either abroad or in institutions. More detailed descriptions of the SHARE/SHARELIFE methodology are also available in the Appendix, the literature, ${ }^{24-28}$ and via www.share-project.org.

Our analyses were based on SHARE wave 5 data on the number of teeth remaining for each participant. Participants were asked: "Do you still have ALL your natural teeth (except wisdom teeth)?". The interviewer informed the participant that "Normally, a person has 28 teeth and 4 wisdom teeth. We are not interested in wisdom teeth." Response options were "Yes" and "No". Participants who reported not having all natural teeth, were further questioned: "About how many natural teeth are you missing?". Respondents' number of natural teeth was derived accordingly. We used this measure as a continuous (limited) dependent variable in a series of regression models in order to detect the extent to which factors from different stages across the life course relate to the number of teeth at age $50+$. 
Based on the rationale that early life conditions and adverse events may impact on later oral health outcomes, the models were built so that they included sequential adjustment for covariates at chronologically different periods of the life course, from early life to more recent determinants. Model specification was informed by a recent SHARE study that examined life-course influences on chewing ability at age $50+{ }^{18}$ Although life history information in wave 3 is slightly more detailed, SHARE wave 5 includes all relevant life history information for our analyses. ${ }^{29}$ Only a small proportion of respondents participated in both SHARE waves 3 and 5. As it provides the most consistent set of data and widest possible inclusion of study participants, our main analysis uses life-history data from SHARE wave 5. The two model specifications at the core of our analyses are described below.

Model A accounted for childhood influences, that is socioeconomic position (SEP) and cognitive skills. More specifically, the model included the following explanatory variables:

Number of rooms per household member at age 10 years (count variable): SEP determinant; Having more than 25 books in the household at age 10 years (yes/no): proxy for scholarly circumstances in household and SEP determinant;

Childhood maths skills at age 10 years (much worse; worse; similar to; better than; or much better than that of peers). This parameter may partly reflect cognitive ability and also represents skills which are important for the formation of oral health literacy;

Financial situation of family from birth to age 15 years (pretty well off; about average; poor; it varied): SEP determinant depicting wealth and monetary circumstances.

Model B additionally controlled for the following parameters which represent conditions at the time of interview (age 50+):

Equivalized income (tertiles within each country's distribution of equivalized household income; OECD square root approach ${ }^{30}$ ): indicates the respondents' current relative SEP within country of residence. Based on the assumption that an individual's wellbeing depends mostly on relative rather than absolute income, it also allows for inter-country comparisons;

Current dental attendance (yes/no): measures whether the respondent had visited a dentist within the past 12 months; 
Self-rated general health (poor; fair; good; very good; or excellent). We included this global rating of general health, as there is strong evidence on the associations between general and oral health; ${ }^{31-33}$ Grip strength (of the dominant hand, in kilograms), in order to depict the current level of functioning ability and lack of frailty. This may be relevant for activities such as oral hygiene. ${ }^{34}$

All models were adjusted for respondents' age and sex, and included country dummies (in the sense of country fixed effects) in order to control for demographic and cross-country influences, and a control variable for whether respondents were born before or after 1946, in order to check for any influence of World War II. To further test the robustness of associations between childhood socioeconomic position and the number of teeth at age 50+, we included educational attainment according to the International Standard Classification of Education as an explanatory SEP determinant in addition to (and also as an alternative to) income. ${ }^{35}$

Based on the specifications described above, linear regression analysis was carried out modelling the average number of teeth conditional on covariates. Linear regressions may yield inconsistent results if the dependent variable is bounded from above or below, such as the number of teeth, and is therefore a non-linear function of the covariates. ${ }^{36}$ Moreover, predicted values can lie outside the feasible interval $[0,28]$. As previously shown for the distribution of the number of natural teeth in SHARE wave 5, the most frequent values are the extremes (zero and 28 teeth, respectively; also see figure 1 ). ${ }^{25}$ Therefore, as an alternative model specification, two-limit Tobit regressions were estimated with "oral health" as a latent dependent variable and the observable counterpart, number of teeth, being censored at a lower bound of 0 teeth and at an upper bound of 28 teeth. The two-limit Tobit model assumes that oral health also differs among study participants at the lower and upper bounds and that covariates are related to these unobservable differences in the same way that they are related to the observable differences. Under this assumption, the Tobit model conceptually takes into account unobserved variation in oral health status that could not be captured in standard linear or negative binomial regression analysis. ${ }^{36}$

All data analyses were carried out in STATA/SE 12.0 (StataCorp, USA). Heteroscedasticity-consistent (robust) standard errors were used throughout. As a further robustness check, the linear regression analysis was re-run using calibrated weights to obtain population-representative estimates. 


\section{RESULTS}

Figure 1 depicts the distribution of the outcome variable (number of observations per number of teeth) for all countries together and for each country individually. With an average of more than 20 remaining teeth, the highest mean numbers of remaining teeth were found for Sweden, Denmark, and Switzerland. The lowest mean numbers of remaining teeth were found for Estonia and Slovenia (average of 16 or fewer remaining teeth).

Table 1 presents average numbers of natural teeth by the various independent variables used in subsequent analyses. The number of teeth varied comparably little with respect to the demographic characteristics (age and sex). Respondents who had more than 25 books in their childhood household had an average of 21 teeth while respondents with fewer books had on average 17 teeth. The average number of teeth differed by childhood financial situation. There were also differences with regard to the average number of rooms per person in the childhood household and the reported level of maths skills in childhood. Respondents with dental attendance during the previous year had 21 teeth; whereas those without recent dental attendance had on average 15 teeth. The number of teeth also varied by current general health status, grip strength, and current income.

Table 2a shows the outcome of linear regressions on the self-reported number of teeth. Model A (left panel) includes only early life determinants as explanatory variables and indicates that respondents with more than 25 books in the childhood household had significantly more teeth than respondents with 25 or fewer books. Relative to respondents who were well off financially in childhood, those who reported their childhood financial situation as poor and those who had a varying childhood financial situation had fewer teeth. The mean number of teeth was greater per additional room per person in the childhood 
household. Relative to the lowest category of childhood maths skills ("much worse than peers"), respondents had significantly more teeth if their childhood maths skills were "better" or "much better" than their peers.

After introducing current independent variables at age 50+ (Model B, right panel), these showed stronger associations than early life variables, for which the size of the estimates was considerably lower. Respondents with more than 25 books in the childhood household had significantly more teeth than those with 25 or fewer books. Relative to respondents who were "pretty well off financially" in childhood, those who described their childhood financial situation as poor had significantly fewer teeth. The mean number of teeth was significantly greater per additional room per person in the childhood household. Respondents who reported recent dental attendance at age 50+ had significantly more teeth than respondents who did not. There was a gradient in the number of teeth and general health. Relative to those with poor general health status, those with excellent general health had significantly more teeth remaining by age $50+$. The number of teeth differed significantly by grip strength in the dominant hand. Relative to respondents from the lowest income tertile, persons from the highest income tertile had significantly more teeth.

Table $2 \mathrm{~b}$ shows the findings from the Tobit regression analysis (partial effects, valued at the sample means of the covariates). The outcomes were similar to those from the linear regressions, with only small differences in the statistical significance level and the size of parameter estimates. Differences in statistical significance level occurred only for one of the parameter estimates for childhood financial situation (significant parameter estimate for the comparison of "it varied" vs. "pretty well off" in the Tobit but not in the linear regression model) and for one of the parameter estimates for childhood maths skills (significant parameter estimate for the comparison of "much better than peers" vs. "much worse than peers" in the linear but not in the Tobit regression model). Inclusion of educational attainment as an explanatory variable in addition to (and as an alternative to) income yielded similar results with regard 
to the parameter estimates for childhood socioeconomic position.

The re-run of the linear regression analysis using calibrated weights to obtain population-representative estimates yielded very similar findings (results available upon request).

\section{DISCUSSION}

Based on unique data from SHARE wave 5, the number of natural teeth at age 50+ was associated with the financial situation in childhood, the number of books, and the number of rooms per person in the childhood household. These findings held robustly after inclusion of oral health determinants (at age $50+)$; dental attendance at age 50+ was the single most important explanatory variable for the number of teeth at age 50+; the number of teeth also differed by general health status and grip strength, and it was also positively associated with contemporary income level.

Some limitations of our study should be noted. Data collected on childhood circumstances, current health status and dental visits may be subject to information bias. In particular, life-history data came from a retrospective survey which may be subject to recall bias. We cannot fully rule out such influences but previous evidence suggests that SHARE study participants remember circumstances in early life reasonably well. ${ }^{37}$ It was previously shown that important SHARELIFE data components are strongly consistent with information reported at the time of occurrence of the events, with less than $10 \%$ recall errors over all events. ${ }^{38}$ The validity of the SHARE measure for self-reported tooth count could not be assessed across countries due to lack of clinical data availability. Previous evidence suggests reasonable accuracy for the self-reported number of teeth in population surveys and close agreement between clinically recorded and self-reported number of teeth. ${ }^{39-43}$ In the present study, however, participants were not asked directly to count their natural teeth. Information on number of teeth was derived from a question about whether or not having all teeth followed by a question about how many teeth were missing. To date, the oral health components in SHARE have not been systematically validated. 
Moreover, our empirical models could account only for influences for which data were available. Some caution should therefore be applied when interpreting parameter estimates because only a limited amount of variation could be explained by the available variables, and it is acknowledged that the number of teeth at age 50+ may also be determined by factors that could not be controlled for in this study. For example, SHARE contains no information on oral health in childhood. As such it is not possible to determine potential associations between childhood oral health and oral health at age 50+. Another caveat is that the retrospective life history element in SHARE wave 5 contained limited information on respondents' living conditions between childhood and current age (50+). Even though childhood socioeconomic conditions could shape the formation of oral health behaviours throughout the entire life course and the present study could control for potential continuity of socioeconomic position from childhood into adulthood, other life-course events or circumstances after childhood may have independent impacts on retaining teeth into older adulthood. ${ }^{44}$ Therefore, the reported associations between the number of teeth and independent variables which represent oral health risk proxies should not be interpreted as causal. Causal inference was beyond the scope of the present study and we did not seek to relate our findings to theoretical models which describe pathways linking life-course exposures to later health and disease. Notwithstanding these limitations, SHARE wave 5 data provide a novel and unique resource for studying early life socioeconomic conditions in relation to oral health in older adulthood. There currently is no comparable data source available with large-scale life history information from multiple countries and information on the number of teeth in older adulthood.

The findings of this study add to the previous empirical evidence on the impact of childhood socioeconomic conditions on oral health in later life. ${ }^{12-19,45}$ Our analyses included different measures for childhood socioeconomic position. Poor or unstable financial conditions in the childhood household had a negative impact on number of natural teeth remaining by age $50+$. Various pathways could be proposed to explain the role of financial conditions in childhood. On the one hand, unfavourable 
financial circumstances in early life could imply limited capacity to afford dental care and hence lead to restrictions in access to dental care. Yet it is important to be aware of differences between countries in oral health care systems. For example, Sweden and Denmark have been having free dental care systems for decades. As such it seems unlikely that children's access to care would have largely been affected by affordability of care in these countries. On the other hand, financial poverty in childhood may have imposed constraints on family life which may in turn impact on a number of more direct risks such as diet quality, psychosocial stress, or oral health behaviours; other issues in life may have been perceived to be of more immediate existential relevance than paying attention to oral health.

The number of books in the childhood household also showed a consistently significant association with number of natural teeth remaining by later adulthood. A book-oriented scholarly culture at home may be relevant for the formation of health literacy, general attitudes to health, and associated health behaviors. $^{46}$

These findings are novel in that they refer to a longer time perspective to understanding life-course differences in oral health than possible heretofore on the basis of longitudinal (birth-cohort) and retrospective (life history) studies. $^{8}$ So far, existing birth cohort studies collecting oral health information have not had sufficient time to follow up individuals into later adulthood. Moreover, previous evidence from European retrospective survey data on life history has been restricted to using a binary measure of chewing ability as an oral health proxy. ${ }^{18}$ In contrast, the present paper draws on a more detailed and clinically relevant oral health outcome measure - the number of teeth.

The findings from the Tobit models were similar to the corresponding linear regression estimates. Interestingly, however, there was a difference in significance for two parameter estimates. The Tobit model, but not the linear regression model, indicated that varying childhood financial condition was significantly associated with number of teeth at age 50+. On the other hand, only the linear regression model, but not the Tobit model, indicated that the highest level of childhood maths skills were 
significantly associated with number of teeth at age 50+. In other words, the linear regression model gave more emphasis to the role of cognitive ability in childhood and skills relevant for formation of oral health literacy, whereas the Tobit model gave more emphasis to the role of wealth and monetary circumstances in early life years. By and large, however, the results of both model specifications support the view that various dimensions of childhood conditions, particularly SEP, are associated with oral health in middle and later adulthood. This information is necessary for health policy-makers to understand the benefits of promoting a healthy early life environment on long-term tooth retention and the associated quality of life and wellbeing among older populations. For example, investments into integrated school campaigns may promote better oral health behaviours in the long run, irrespective of children's socioeconomic background, and hence pay off across all of life.

Given the limitations of the present study, it would be premature to attempt to interpret the findings as proof in support of or against any of the previously proposed theoretical life-course models (critical period model, sensitive period model, accumulation of risk model, chain of risk model). ${ }^{8}$ However, the findings emphasize that early life conditions, particularly SEP, are important for later oral health, so they underline the relevance of future life-course analyses for understanding oral health. Future research is also warranted to examine the precise properties of the oral health measures in SHARE, particularly with regard to the validity of the number of (missing) teeth variable and in terms of cross-country comparability.

In conclusion, the study highlights the relevance of childhood socioeconomic conditions for tooth retention into older adulthood. This may be important information for health policy makers to better understand the benefits of promoting adequate early life conditions on long-term tooth retention and associated influences on quality of life and wellbeing of older populations. The need for public health interventions focusing on early life circumstances ${ }^{47,48}$ and their importance for maintaining good oral 
health throughout the entire life course is emphasized.

\section{Acknowledgements}

The authors received no financial support and declare no potential conflicts of interest with respect to the authorship and/or publication of this article. This paper uses data from SHARE Wave 5 release 1.0.0, as of March 31st 2015 (DOI: 10.6103/SHARE.w5.100) or SHARE Wave 4 release 1.1.1, as of March 28th 2013 (DOI: 10.6103/SHARE.w4.111) or SHARE Waves 1 and 2 release 2.6.0, as of November 29th 2013 (DOI: 10.6103/SHARE.w1.260 and 10.6103/SHARE.w2.260) or SHARELIFE release 1.0.0, as of November 24th 2010 (DOI: 10.6103/SHARE.w3.100). The SHARE data collection has been primarily funded by the European Commission through the 5th Framework Programme (project QLK6CT-2001-00360 in the thematic programme Quality of Life), through the 6th Framework Programme (projects SHARE-I3, RII-CT-2006-062193, COMPARE, CIT5- CT-2005-028857, and SHARELIFE, CIT4-CT-2006-028812) and through the 7th Framework Programme (SHARE-PREP, N ${ }^{\circ} 211909$, SHARE-LEAP, $\mathrm{N}^{\circ} 227822$ and SHARE M4, N 261982). Additional funding from the U.S. National Institute on Aging (U01 AG09740-13S2, P01 AG005842, P01 AG08291, P30 AG12815, R21 AG025169, Y1-AG-4553-01, IAG BSR06-11 and OGHA 04-064) and the German Ministry of Education and Research as well as from various national sources is gratefully acknowledged (see www.share-project.org for a full list of funding institutions) 


\section{References}

1. Marcenes W, Kassebaum NJ, Bernabé E, Flaxman A, Naghavi M, Lopez A, Murray CJ. Global burden of oral conditions in 1990-2010: a systematic analysis. J Dent Res 2013; 92:592-597.

2. Listl S, Galloway J, Mossey PA, Marcenes W. Global economic impact of dental diseases. J Dent Res 2015; 94:1355-61

3. Chauncey HH, Muench ME, Kapur KK, Wayler AH. The effect of the loss of teeth on diet and nutrition. Int Dent J 1984; 34: 98-104.

4. Moynihan P. The interrelationship between diet and oral health. Proc Nutr Soc 2005; 64: 571-80.

5. Kuh D, Ben-Shlomo Y. The life course approach to chronic disease epidemiology. $2^{\text {nd }}$ edition. Oxford 2004: Oxford University Press.

6. Lynch J, Davey Smith G. A life course approach to chronic disease epidemiology. Annu. Rev. Public Health 2005; 26: 1-35.

7. Blane D, Netuveli G, Stone J. The development of life course epidemiology. Rev Epidemiol Sante Publique 2007; 55: 31-38.

8. Peres MA, Listl S, Heilmann A. Lifecourse oral health epidemiology. In: Watt RG, Listl S, Peres MA, Heilmann A, editors. Social inequalities in oral health: from evidence to action. London 2015: International Centre for Oral Health Inequalities Research \& Policy. p. 16-17.

9. Pearce MS, Unwin NC, Parker L, Craft AW. Cohort profile: the Newcastle Thousand Families 1947 birth cohort. Int J Epidemiol 2009; 38: 932-937.

10. Silva PA, Stanton WR. From child to adult: the Dunedin Multidisciplinary Health and Development Study. Auckland 1996: Oxford University Press.

11. Barros AJ, Santos IS, Matijasevich A, Araújo CL, Gigante DP, Menezes AM, Horta BL, Tomasi E, Victora CG, Barros FC. Methods used in the 1982, 1993, and 2004 birth cohort studies from Pelotas, Rio Grande do Sul State, Brazil, and a description of the socioeconomic conditions of participants' families. Cad Saude Publica 2008; 24(3 Suppl.):371S-380S.

12. Poulton R, Caspi A, Milne BJ, Thomson WM, Taylor A, Sears MR, Moffitt TE. Association between children's experience of socioeconomic disadvantage and adult health: a life-course study. Lancet 2002; 360(9346):1640-1645.

13. Thomson WM, Poulton R, Milne BJ, Caspi A, Broughton JR, Ayers KM. Socioeconomic inequalities in oral health in childhood and adulthood in a birth cohort. Community Dent Oral Epidemiol 2004; 32: 345-353. 
14. Pearce MS, Steele JG, Mason J, Walls AW, Parker L. Do circumstances in early life contribute to tooth retention in middle age? J Dent Res 2004; 83: 562-566.

15. Peres MA, Thomson WM, Peres KG, Gigante DP, Horta BL, Broadbent JM, Poulton R. 2011 a. Challenges in comparing the methods and findings of cohort studies of oral health: the Dunedin (New Zealand) and Pelotas (Brazil) studies. Aust N Z J Public Health. 2011; 35: 549-556.

16. Gülcan F, Ekbäck G, Ordell S, Lie SA, Astrom AN. Inequality in oral health related to early and later life social conditions: a study of elderly in Norway and Sweden. BMC Oral Health 2015; 15: 20.

17. Astrom AN, Ekbäck G, Lie SA, Ordell S. Life-course social influences on tooth loss and oral attitudes among older people: evidence from a prospective cohort study. Eur J Oral Sci 2015; 123:30-38.

18. Listl S, Watt RG, Tsakos G. Early life conditions, adverse life events, and chewing ability at middle and later adulthood. Am J Public Health 2014; 104:e55-e61.

19. Steele J, Shen J, Tsakos G, Fuller E, Morris S, Watt R, Guarnizo-Herreno C, Wildman J. The interplay between socioeconomic inequalities and clinical oral health. J Dent Res 2015; 94: 19-26.

20. Zitzmann NU, Staehelin K, Walls AW, Menghini G, Weiger R, Zemp Stutz E. Changes in oral health over a 10-yr period in Switzerland. Eur J Oral Sci 2008; 116: 52-59.

21. Wennstrom A, Ahlqwist M, Stenman U, Bjorkelund C, Hakeberg M. Trends in tooth loss in relation to socio-economic status among Swedish women, aged 38 and 50 years: repeated cross-sectional surveys 1968-2004. BMC Oral Health 2013; 13: 63.

22. Müller F, Naharro M, Carlsson GE. What are the prevalence and incidence of tooth loss in the adult and elderly population in Europe? Clin Oral Implants Res 2007; 18(Suppl 3): 2-14.

23. Schneider C, Zemp E, Zitzmann NU. Oral health improvements in Switzerland over 20 years. Eur J Oral Sci 2017; 125: 55-62.

24. Gerritsen AE, Allen PF, Witter DJ, Bronkhorst EM, Creugers NH. Tooth loss and oral health-related quality of life: a systematic review and meta-analysis. Health Qual Life Outcomes. 2010 Nov 5;8:126.

25. Stock C, Jürges H, Shen J, Bozorgmehr K, Listl S. A comparison of tooth retention and replacement across 15 countries in the over-50s. Community Dent Oral Epidemiol 2016; 44:223-232.

26. Börsch-Supan, A., M. Brandt, C. Hunkler, T. Kneip, J. Korbmacher, F. Malter, B. Schaan, S. Stuck, and S. Zuber. Data Resource Profile: The Survey of Health, Ageing and Retirement in Europe (SHARE). Int J Epidemiol 2013; 42:1-10.

27. Kneip T, Malter F, Sand G. Fieldwork monitoring and survey participation in fifth wave of SHARE. In: Malter F, Börsch-Supan A, editors. SHARE Wave 5: Innovations \& Methodology. Munich, Germany: Munich Center for the Economics of Aging (MEA) at the Max Planck Institute for Social Law and Social Policy (MPISOC); 2015. 
28. Listl S, Jürges H. Social inequalities in oral health - towards targeted health policy interventions. In: Börsch-Supan A, et al. (eds) SHARE: A European policy device for inclusive ageing societies, De Gruyter: 2015. [forthcoming]

29. Malter F, Börsch-Supan, A, editors. 2015. SHARE Wave 5: Innovations \& Methodology. Munich: MEA, Max Planck Institute for Social Law and Social Policy. [accessed 2016 October $30^{\text {th }}$ ]. http://www.share-project.org/fileadmin/pdf documentation/Method vol5 31March2015.pdf

30. OECD. OECD Framework for Statistics on the Distribution of Household Income, Consumption and Wealth; [accessed 2016 October 30th]. http://www.oecd.org/statistics/OECD-ICW-FrameworkChapter8.pdf

31. Watt RG, Tsakos G, de Oliveira C, Hamer M. Tooth loss and cardiovascular disease mortality riskresults from the Scottish Health Survey. PLoS ONE. 2012;7(2):e30797.

32. Tu YK, Galobardes B, Smith GD, McCarron P, Jeffreys M, Gilthorpe MS. Associations between tooth loss and mortality patterns in the Glasgow Alumni Cohort. Heart. 2007;93(9):1098-1103.

33. Aida J, Kondo K, Yamamoto T. et al. Oral health and cancer, cardiovascular, and respiratory mortality of Japanese. J Dent Res. 2011;90(9):1129-1135.

34. Padilha, D. M. P., Hugo, F. N., Hilgert, J. B. and Dal Moro, R. G. (2007), Hand Function and Oral Hygiene in Older Institutionalized Brazilians. Journal of the American Geriatrics Society, 55: 13331338.

35. UNESCO. International Standard Classification of Education; [accessed 2016 October 30th]. http://www.unesco.org/education/information/nfsunesco/doc/isced_1997.htm

36. Wooldridge JM. Econometric Analysis of Cross Section and Panel Data. Cambridge, MA; 2002: MIT Press.

37. Havari E, Mazzona F. Can we trust older peoples' statements on their childhood circumstances? Evidence from SHARELIFE. SHARE Working Paper Series 2011; 05-2011.

38. Garrouste C, Paccagnella O. Data Quality: Three Examples of Consistency across SHARE and SHARELIFE Data. In: Schröder M. Retrospective Data Collection in the Survey of Health, Ageing and Retirement in Europe. SHARELIFE Methodology. Mannheim: MEA. Available online via: http://www.share-project.org/fileadmin/pdf_sharelife/Publications/FRB-

Methodology feb2011 color-1.pdf

39. Ramos RQ, Bastos JL, Peres MA. Diagnostic validity of self-reported oral health outcomes in population surveys: literature review. Rev Bras Epidemiol 2013; 16: 716-728.

40. Douglass CW, Berlin J, Tennstedt S. The validity of self-reported oral health status in the elderly. J Public Health Dent. 1991;51:220-2. 
41. Gilbert GH, Duncan RP, Kulley AM. Validity of self-reported tooth counts during a telephone screening interview. J Public Health Dent. 1997;57:176-80.

42. Pitiphat W, Garcia RI, Douglass CW, Joshipura KJ. Validation of self-reported oral health measures. J Public Health Dent. 2002;62:122-8.

43. Ueno M, Zaitsu T, Shinada K, Ohara S, Kawaguchi Y. Validity of the self-reported number of natural teeth in Japanese adults. J Investig Clin Dent. 2010;1:79-84.

44. Peres MA, Peres KG, Thomson WM, Broadbent JM, Gigante DP, Horta BL. The influence of family income trajectories from birth to adulthood on adult oral health: findings from the 1982 Pelotas birth cohort. Am J Public Health 2011; 101: 730-736.

45. Bernabé E, Suominen AL, Nordblad A, Vehkalahti MM, Hausen H, Knuuttila M, Kivimki M, Watt RG, Sheiham A, Tsakos G. Education level and oral health in Finnish adults: evidence from different lifecourse models. J Clin Periodontol 2011; 38: 25-32.

46. Sanders LM, Zacur G, Haecker T, Klass P. Number of children's books in the home: an indicator of parent health literacy. Ambul Pediatr 2004; 4: 424-428.

47. Marmot MG, Allen J, Goldblatt P, Boyce T, McNeish D, Grady M, Geddes I. Fair society, healthy lives: Strategic review of health inequalities in England post-2010. London 2010; [accessed 2016 October 30th]. http://www.instituteofhealthequity.org/projects/fair-societyhealthy-lives-the-marmotreview.

48. Case A, Paxson C. The long reach of childhood health and circumstance: evidence from the Whitehall II Study. Econ J 2011; 121:F183-F204.

49. Steele JG, Treasure ET, O'Sullivan I, Morris J, Murray JJ. Adult Dental Health Survey 2009: transformations in British oral health 1968-2009. Br Dent J 2012; 213: 523-527. 


\section{Table legends}

Table 1: Mean number of natural teeth by covariates

Table 2a: Outcome of multivariable linear regressions for the number of natural teeth

Table 2b: Outcome of Tobit regressions for the number of natural teeth (partial effects, valued at the sample means of the covariates) 
Page 21 of 23 Table 1: Mean number of natufal teeth by covariates

\begin{tabular}{|c|c|c|}
\hline & $\begin{array}{c}\text { Number of teeth } \\
\text { Mean (std.dev.) }\end{array}$ & $\mathbf{N}$ \\
\hline \multicolumn{3}{|l|}{ Age } \\
\hline$\ldots .50$ to 65 years old & $18.4(10.1)$ & 25,081 \\
\hline$\ldots 66$ to 80 years old & $18.4(10.2)$ & 23,570 \\
\hline Sex $\quad \ldots 80$ years and older & $18.3(10.2)$ & 7,269 \\
\hline ...women & $18.5(10.2)$ & 30,852 \\
\hline ...men & $18.3(10.1)$ & 25,068 \\
\hline \multicolumn{3}{|l|}{ Number of books in childhood household } \\
\hline$\ldots 25$ or fewer & $16.9(10.4)$ & 24,206 \\
\hline$\ldots 26$ or more & $20.8(9.1)$ & 18,231 \\
\hline \multicolumn{3}{|l|}{ Childhood financial situation... } \\
\hline ...pretty well off & $20.3(9.5)$ & 5,430 \\
\hline ... about average & $19.2(9.8)$ & 25,874 \\
\hline ... poor & $16.0(10.5)$ & 10,737 \\
\hline$\ldots$ it varied & $18.2(10.2)$ & 790 \\
\hline \multicolumn{3}{|l|}{ \# rooms per person in childhood household } \\
\hline ...fewer than 1 & $18.2(10.1)$ & 36,474 \\
\hline$\ldots 1$ or more & $21.1(9.0)$ & 6,029 \\
\hline \multicolumn{3}{|l|}{ Childhood math skills were ... } \\
\hline ...much worse than peers & $16.9(10.5)$ & 807 \\
\hline ...worse than peers & $17.8(10.3)$ & 4,716 \\
\hline ...similar to peers & $18.5(10.1)$ & 23,033 \\
\hline ...better than peers & $19.2(9.8)$ & 9,577 \\
\hline ...much better than peers & $19.3(9.7)$ & 4,190 \\
\hline \multicolumn{3}{|l|}{ Recent dental attendance (age $50+$ ) } \\
\hline ...yes & $21.0(8.4)$ & 32,282 \\
\hline ...no & $14.8(11.1)$ & 23,638 \\
\hline \multicolumn{3}{|l|}{ Current general health (age $50+$ ) is ... } \\
\hline ...poor & $13.1(10.7)$ & 4,328 \\
\hline ...fair & $15.4(10.5)$ & 14,590 \\
\hline ...good & $18.8(9.8)$ & 21,336 \\
\hline ...very good & $21.9(8.5)$ & 10,558 \\
\hline ...excellent & $22.8(8.1)$ & 5,108 \\
\hline \multicolumn{3}{|l|}{ Grip strength (in kg; dominant hand; age $50+$ ) } \\
\hline ...less than $25 \mathrm{~kg}$ & $15.9(10.9)$ & 15,674 \\
\hline$\ldots 25$ to less than $40 \mathrm{~kg}$ & $18.9(9.9)$ & 25,384 \\
\hline$\ldots 40 \mathrm{~kg}$ or more & $20.2(9.1)$ & 14,862 \\
\hline \multicolumn{3}{|l|}{ Equivalized income (age $50+$ ) } \\
\hline$\ldots 1^{\text {st }}$ tertile (within-country income) & $16.2(10.6)$ & 18,829 \\
\hline$\ldots 2^{\text {nd }}$ tertile (within-country income) & $18.8(9.9)$ & 17,375 \\
\hline$\ldots 3^{\text {rd }}$ tertile (within-country income) & $20.2(9.4)$ & 19,716 \\
\hline \multicolumn{3}{|l|}{ Educational attainment (ISCED scores) } \\
\hline ...(pre-)primary (ISCED scores 0 and 1$)$ & $18.3(10.1)$ & 8,260 \\
\hline ...secondary (ISCED scores 2 and 3 ) & $18.5(10.1)$ & 32,139 \\
\hline ... post-secondary (ISCED scores 4-6) & $18.3(10.1)$ & 15,521 \\
\hline
\end{tabular}




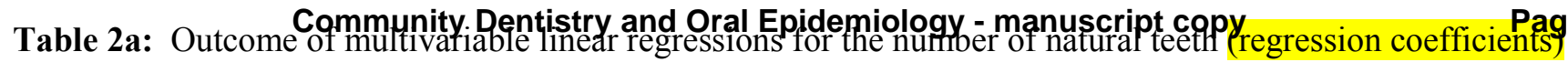

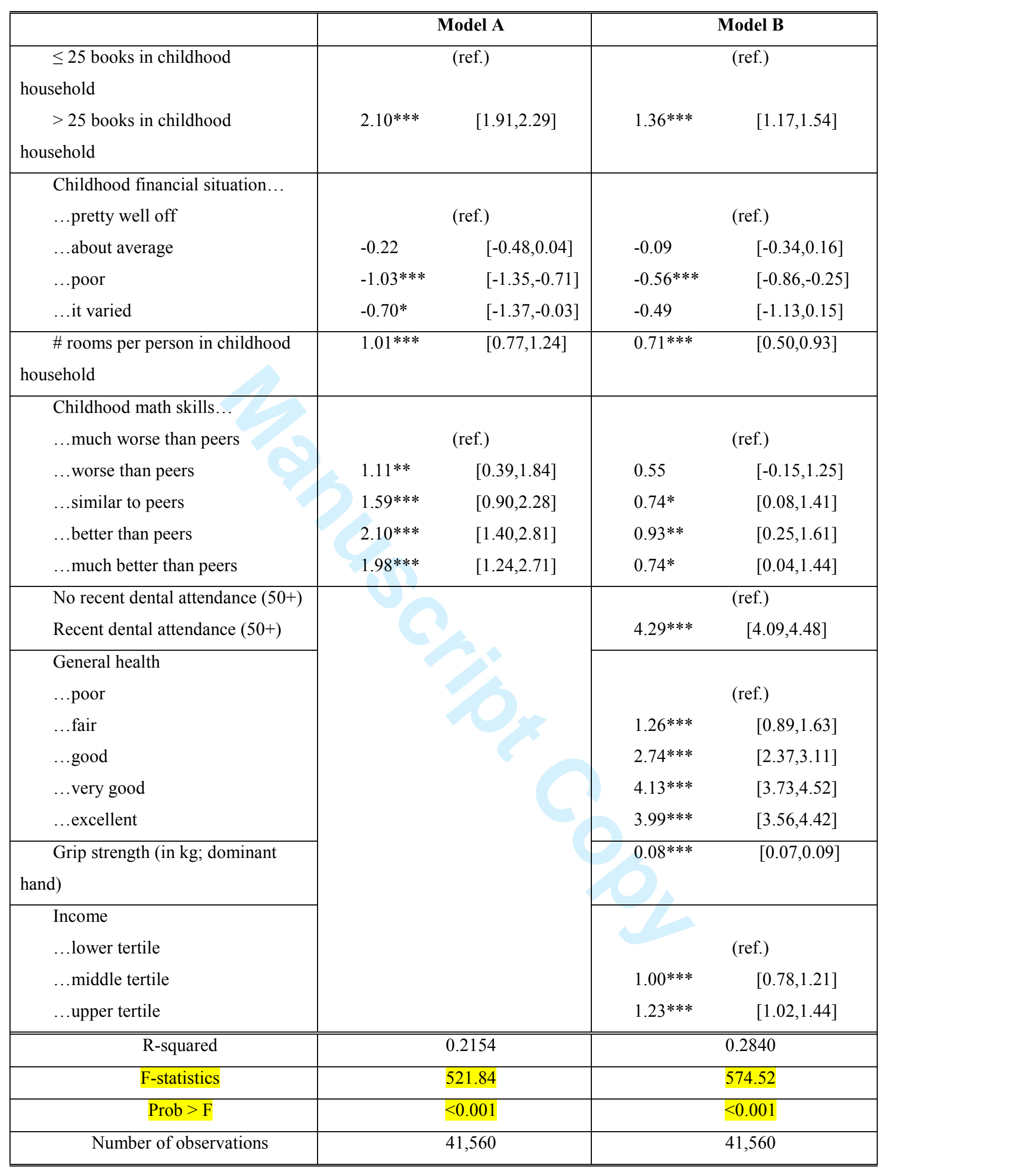

Model A accounted for childhood influences, i.e. socioeconomic position (SEP) and cognitive skills; Model B additionally controlled for parameters which represent conditions at the time of interview (age 50+); 95\% confidence intervals in parentheses; $* \mathrm{p}<0.05, * * \mathrm{p}<0.01, * * *$ $\mathrm{p}<0.001$; all models include control variables for age, sex, country dummies and a control variable for being born before the year 1946 or thereafter. 
Table 2b: Outcome of Tobit regressions for the number of natural teeth (partial effects, valued at the sample means of the covariates)

\begin{tabular}{|c|c|c|c|c|}
\hline & \multicolumn{2}{|c|}{ Model A } & \multicolumn{2}{|c|}{ Model B } \\
\hline$\leq 25$ books in childhood household & \multicolumn{2}{|c|}{ (ref.) } & \multicolumn{2}{|c|}{ (ref.) } \\
\hline$>25$ books in childhood household & $2.80 * * *$ & {$[2.61,2.99]$} & $1.25 * * *$ & {$[1.07,1.42]$} \\
\hline $\begin{array}{l}\text { Childhood financial situation... } \\
\text {...pretty well off }\end{array}$ & \multicolumn{2}{|c|}{ (ref.) } & \multicolumn{2}{|c|}{ (ref.) } \\
\hline ...about average & -0.06 & {$[-0.34,0.21]$} & -0.19 & {$[-0.44,0.05]$} \\
\hline ...poor & $-1.42 * * *$ & {$[-1.74,-1.10]$} & $-0.61 * * *$ & {$[-0.90,-0.33]$} \\
\hline ...it varied & $-1.08 * *$ & {$[-1.75,-0.42]$} & $-0.65^{*}$ & {$[-1.25,-0.05]$} \\
\hline $\begin{array}{l}\text { \# rooms per person in childhood } \\
\text { household }\end{array}$ & $1.34 * * *$ & {$[1.06,1.61]$} & $0.78 * * *$ & {$[0.56,0.99]$} \\
\hline $\begin{array}{l}\text { Childhood math skills... } \\
\text {...much worse than peers }\end{array}$ & \multicolumn{2}{|c|}{ (ref.) } & \multicolumn{2}{|c|}{ (ref.) } \\
\hline ...worse than peers & $1.06^{* *}$ & {$[-0.36,1.75]$} & 0.57 & {$[-0.07,1.21]$} \\
\hline ...similar to peers & $1.27 * * *$ & {$[0.62,1.93]$} & $0.72 *$ & {$[0.11,1.32]$} \\
\hline ...better than peers & $1.61 * * *$ & {$[0.94,2.28]$} & $0.83 * *$ & {$[0.22,1.45]$} \\
\hline ...much better than peers & $1.35 * * *$ & {$[0.65,2.04]$} & 0.59 & {$[-0.05,1.23]$} \\
\hline No recent dental attendance $(50+)$ & \multirow{13}{*}{ 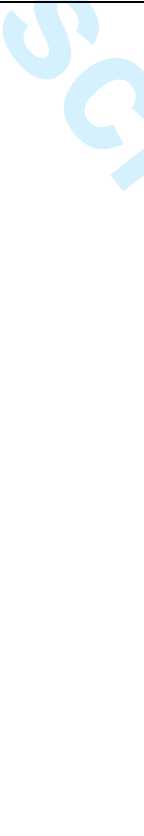 } & & \multicolumn{2}{|c|}{ (ref.) } \\
\hline Recent dental attendance $(50+)$ & & & $3.75^{* * *}$ & {$[3.57,3.92]$} \\
\hline General health & & & \multirow{2}{*}{\multicolumn{2}{|c|}{ (ref.) }} \\
\hline ...poor & & & & \\
\hline ...fair & & & $1.00 * * *$ & {$[0.66,1.33]$} \\
\hline$\ldots$ good & & & $2.23 * * *$ & {$[1.90,2.56]$} \\
\hline ...very good & & & $3.70 * * *$ & {$[3.34,4.06]$} \\
\hline ...excellent & & & $3.69 * * *$ & {$[3.28,4.10]$} \\
\hline $\begin{array}{l}\text { Grip strength (in kg; dominant } \\
\text { hand) }\end{array}$ & & & \multicolumn{2}{|c|}{$[0.06,0.08]$} \\
\hline Income & & & \\
\hline ...lower tertile & & & & \\
\hline ...middle tertile & & & $0.91 * * *$ & {$[0.71,1.11]$} \\
\hline ...upper tertile & & & $1.22 * * *$ & {$[1.03,1.42]$} \\
\hline Number of observations & \multicolumn{2}{|c|}{41,560} & \multicolumn{2}{|c|}{41,560} \\
\hline
\end{tabular}

Model A accounted for childhood influences, i.e. socioeconomic position (SEP) and cognitive skills; Model B additionally controlled for parameters which represent conditions at the time of interview (age 50+); 95\% confidence intervals in parentheses; * $\mathrm{p}<0.05, * * \mathrm{p}<0.01, * * * \mathrm{p}<0.001$; all models include control variables for age, sex, country dummies and a control variable for being born before the year 1946 or thereafter; obs. summary: 5183 left-censored observations at number of teeth $<=0,25953$ uncensored observations, 10424 right-censored observations at number of teeth $>=28$. 

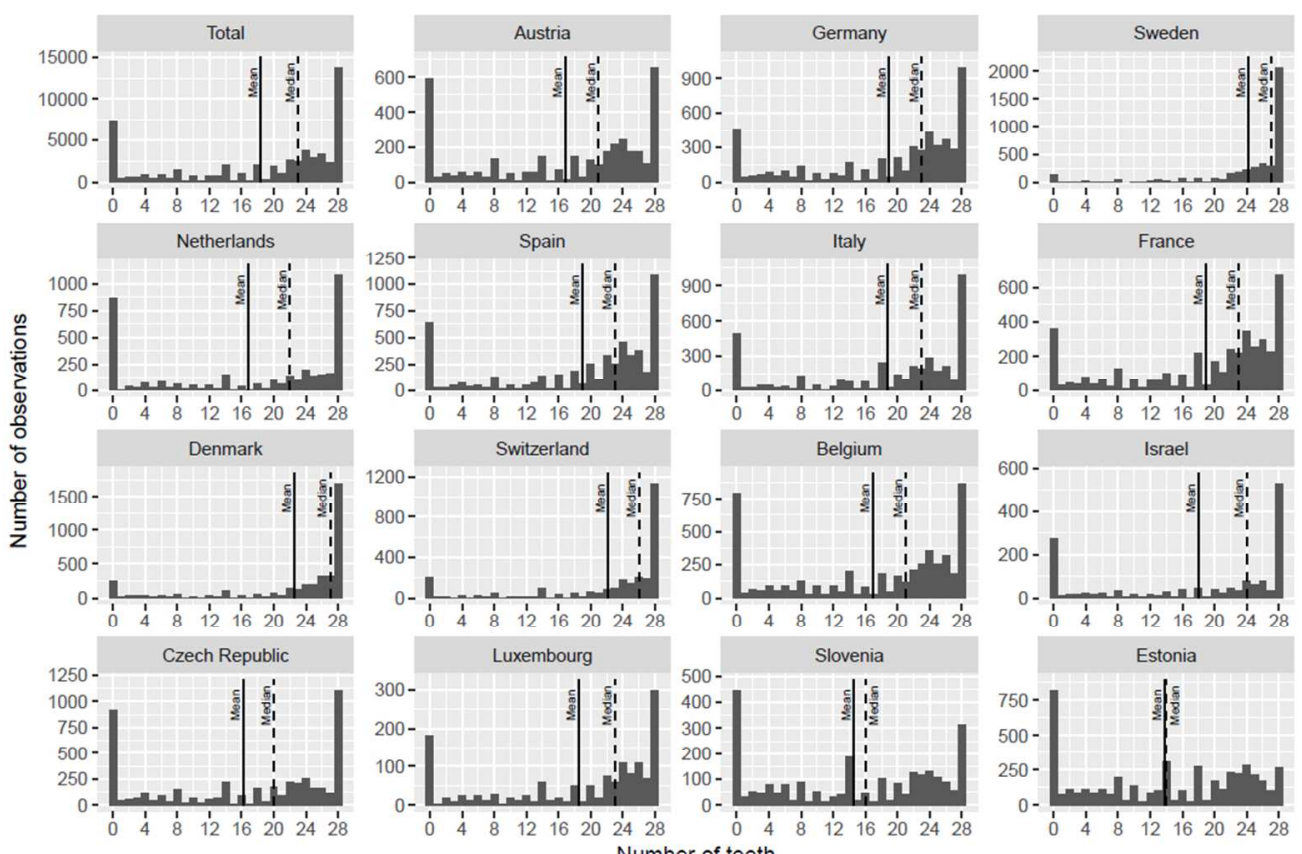